Abstract P2-S1.05 Table 1 Parental acceptability of contraceptive methods

\begin{tabular}{|c|c|c|c|c|}
\hline Contraceptive method & $\begin{array}{l}\text { Overall } \\
\text { parental } \\
\text { acceptability } \\
(\mathrm{N}=\mathbf{2 6 1})\end{array}$ & $\begin{array}{l}\text { Parental acceptability } \\
\text { if teen is very unlikely } \\
\text { to have sex in next } \\
\text { year }(n=195)\end{array}$ & $\begin{array}{l}\text { Parental acceptability } \\
\text { if teen has any likelihood } \\
\text { of having sex in next } \\
\text { year }(n=62)\end{array}$ & $\begin{array}{l}\text { Differences in } \\
\text { acceptability by } \\
\text { likelihood of teen } \\
\text { having sex }\end{array}$ \\
\hline Condom & $51 \%$ & $43 \%$ & $76 \%$ & $\mathrm{p}<0.001$ \\
\hline Oral contraceptive pill (OCP) & $59 \%$ & $53 \%$ & $75 \%$ & $\mathrm{p}<0.01$ \\
\hline Depot medroxyprogesterone Acetate (DMPA) & $46 \%$ & $42 \%$ & $58 \%$ & $\mathrm{p}<0.05$ \\
\hline Patch & $42 \%$ & $39 \%$ & $51 \%$ & NS \\
\hline Implant & $32 \%$ & $30 \%$ & $37 \%$ & NS \\
\hline Intrauterine Device (IUD) & $18 \%$ & $17 \%$ & $20 \%$ & NS \\
\hline Emergency contraception (EC) & $45 \%$ & $39 \%$ & $63 \%$ & $p<0.001$ \\
\hline
\end{tabular}

NS, not statistically significant.

$\mathrm{p}>0.05$.

services at least once/week. When parents were asked about their own experiences as teens, $40 \%$ reported sexual intercourse, $4 \%$ had an STI, $14 \%$ had a teen pregnancy, and 25\% used birth control. The majority of parents lacked STI knowledge (56\% correctly answered $0-1$ out of 5 basic knowledge questions). Overall acceptability of contraception provided to their teen was highest for oral contraceptive pills (OCP) $59 \%$ and condoms $51 \%$ and lowest for IUDs 18\% (see Abstract P1-S2.05 table 1). Only 24\% thought there was any likelihood their teen would have sexual intercourse in the next year. Acceptability of OCPs, condoms, and emergency contraception was higher among parents who report a likelihood their teen would have sex.

Discussion This is the first study to examine parental acceptability of contraception offered during a CV. This study shows that parents lack basic STI knowledge and underestimate their teens' sexual activity. Only half found condoms, the only method that offers both STI and contraception protection, to be acceptable. In the context of providing confidential health services for teens, these findings highlight the need to better understand influences on parental attitudes and to improve communication with parents about sexual health topics, STIs, and condom use.

\section{P2-S1.06 ADOLESCENTS' WILLINGNESS TO PARTICIPATE IN HIV VACCINE CLINICAL TRIAL PREPAREDNESS IN NIGERIA}

doi:10.1136/sextrans-2011-050108.284

${ }^{1} \mathrm{~N}$ Otuonye, ${ }^{1} \mathrm{R}$ Onwuatuelo, ${ }^{1} \mathrm{C}$ Onwuamah. ${ }^{1}$ Nigerian Institute of Medical Research, Yaba, Nigeria

Background Routine vaccination of recommended vaccines in adolescents/children from 1999 would prevent $>14$ million disease cases and 33000 deaths over the lifetime of each birth cohort. Data from National sero-prevalence surveys estimate the prevalence of HIV among 15-24 years old to be $5.2 \%$. Therefore including adolescents in HIV vaccine trials makes them an important target for research in primary prevention of HIV infection which they are increasingly at risk of. This study evaluated adolescent perception towards HIV vaccine trial in Nigeria.

Methods Two hundred and ninety one consenting adolescents were randomly selected for this study. They were recruited from some secondary schools class rooms, university undergraduates' hostels and some traders at the shopping malls within Lagos State Metropolis. Data were collected using semi-structured questionnaire. Information was obtained from knowledge of HIV status, willingness to participate in vaccine trial in future were obtained. Additionally, sexual risk behaviour, stigmatisation, obtain parental permission (required or not required), and function of efficacy of HIV vaccine and perceived self risk of HIV vaccine were collated and analysed using EPI INFO 2002 software (CDC, USA).
Result Of the 291 respondents interviewed, 96\% were single. $72.7 \%$ who were willing to participate in the HIV vaccine trial $(p<0.05)$, were educated $(97.5 \%)$ have Knowledge of HIV vaccine $(73.5 \%)$, and have no perceived risk of HIV vaccine infection from immunisation (66.2\%). Few respondents (31.3\%) know their HIV status. Contrarily, those seeking parental permission $(66.2 \%)$ would significantly reduce willingness to participate $(p>0.05)$.

Conclusion Efforts should be made on sustained education campaigns on HIV vaccine involving adolescents/parents' consent, otherwise there would be potential obstacle to hypothetical vaccine acceptance and believe. Sexual high risk behaviour is an important factor in the retention of adolescents in future vaccine. studies. A number of other ethical and social issues need to be addressed before adolescent HIV vaccine trials in Nigeria.

\section{P2-S1.07 SADNESS, POOR SCHOOL WORK, RUNNING AWAY, AND SEXUAL RISK BEHAVIOUR AMONG URBAN FEMALE AFRICAN AMERICAN ADOLESCENTS}

doi:10.1136/sextrans-2011-050108.285

M Safran, L Hui Tian, M Hogben, J Braxton, R Robitz, E Koumans. Centers for Disease Control and Prevention, CDC, Atlanta, USA

Background Correlations between delinquency, poor school performance, and poor sense of emotional well-being among adolescents are often recognised, but their correlation with risky sexual behaviour has not been as well explored, particularly in African American female populations.

Methods We surveyed 743 sexually active females, age 13 to 19 (mean 16.6 years), attending a predominantly African American urban adolescent clinic. We asked about sexual activity and about poor school work, delinquency (running away from home), poor emotional well-being (feeling unhappy, sad, or depressed), and receiving counselling. To assess associations, ORs were calculated with $95 \%$ CIs. A respondent was classified as having correct and consistent condom use if her responses indicated that, during the past 90 days ALL of the following were true: she had engaged in vaginal sexual intercourse at least once, a condom had been used during all vaginal sexual intercourse, the condom was always put on prior to genital contact and remained on throughout sexual intercourse, a condom had never broken while being worn, and a condom had never been put on inside out and then flipped over and put back on again.

Results Approximately $10 \%$ of females had 0 sexual partners in the past 90 days, $54 \%$ had 1 partner, and $36 \%$ had 2 or more partners. Those responding true to whether they felt unhappy, sad, or depressed in the past 6 months (12\% of the sample) were more likely to report more than one sexual partner compared to those responding "not true", $\mathrm{OR}=2.13$ (95\% CI 1.33-to 3.39), and less 